\title{
Intraventricular recurrence of a craniopharyngioma: case report
}

\author{
Jaclyn J. Renfrow, MD, ${ }^{1}$ Garret P. Greeneway, BA, ${ }^{1}$ Lacey Carter, MD, ${ }^{2}$ and Daniel E. Couture, MD ${ }^{1}$ \\ 1Department of Neurological Surgery, Wake Forest University School of Medicine, Winston-Salem, North Carolina; and \\ ${ }^{2}$ Department of Neurological Surgery, University of Oklahoma, Oklahoma City, Oklahoma
}

\begin{abstract}
Craniopharyngiomas frequently recur locally or less commonly along the path of prior resection. Ectopic recurrence is rare, although cases are reported along the neuraxis spanning from the subgaleal space down to the S1 nerve root. This case reports on a girl with a history of craniopharyngioma first resected at 23 months of age with two local suprasellar recurrences managed with repeat craniotomy and external beam radiation therapy. At age 14 she complained of worsening headaches and brain MRI demonstrated an enhancing 1.2-cm cystic lesion in the posterior body of the left lateral ventricle. Pathology following endoscopic resection of the lesion was consistent with an adamantinomatous craniopharyngioma. This case report serves to describe the first reported recurrence of a craniopharyngioma in the lateral ventricle and emphasizes the need for a high index of suspicion along with long-term follow-up of patients with a history of craniopharyngioma.
\end{abstract}

https://thejns.org/doi/abs/10.3171/2018.4.PEDS18112

KEYWORDS craniopharyngioma; ectopic recurrence; cerebrospinal fluid seeding; pituitary surgery

$\mathrm{C}$ RANIOPHARYNGIOMAS are benign tumors that arise from the squamous epithelial cells of Rathke's pouch, an embryological structure that extends midline connecting the sella to the hypothalamus and floor of the third ventricle. ${ }^{5}$ Craniopharyngiomas are the most prevalent nonglial brain tumors in children and account for approximately $5 \%$ of pediatric brain tumors. ${ }^{12}$ They are typically treated using resection, although it is often challenging due to their invasive tendencies and proximity to the optic chiasm and pituitary stalk. ${ }^{4}$ Despite treatment with resection, recurrence rates are as high as $20 \%-70 \%$. $^{2,9}$ Additionally, there are rare instances of ectopic recurrences due to spread along the surgical route during tumor resection or CSF dissemination reported in the literature. With IRB approval from Wake Forest Baptist Health, we report a unique case of a girl with a previously resected suprasellar craniopharyngioma who developed an ectopic recurrence in the body of the left lateral ventricle.

\section{Case Report}

History, Operation, and Local Recurrences

A 23-month-old girl presented with ataxia, irritability, and vomiting, with obstructive hydrocephalus and a $3-\mathrm{cm}$ enhancing suprasellar mass involving the anterior aspect of the third ventricle and bilateral obstruction of the foramen of Monro. She underwent placement of bilateral external ventricular drains followed by a right frontotemporal craniotomy for resection of an adamantinomatous craniopharyngioma. Intraoperatively this mass was adherent to the proximal portion of the pituitary stalk and optic chiasm. The mass extended into the third ventricle, where it was resected endoscopically with dorsal-ventral borders of the fornix and hypothalamus, respectively. Postoperative imaging demonstrated no residual disease. At age 5 , she underwent a repeat craniotomy for resection of a local recurrence. She did well until she was found to have a second local recurrence at the age of 8 . She was subsequently treated with 5400 cGy of external beam radiation therapy and developed panhypopituitarism and optic nerve atrophy.

\section{Intraventricular Recurrence}

She was followed up with surveillance brain MRI, which at age 14 demonstrated stable postsurgical changes within the sellar region and a 1.2-cm cyst in the left 


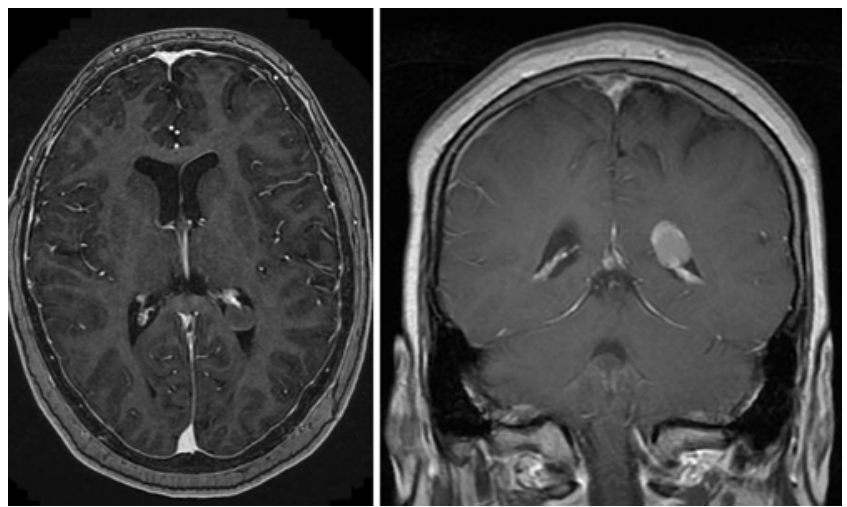

FIG. 1. Enhanced axial (left) and coronal (right) T1-weighted MR images demonstrating a 1.2-cm hyperintense lesion involving the body of the left lateral ventricle associated with the choroid plexus.

lateral ventricles. A hyperintense signal was noted on unenhanced T1-weighted images, likely reflecting proteinaceous material that further enhanced with contrast administration (Fig. 1). The patient was taken to the operating theater for endoscopic resection, with intraoperative findings of an intraventricular tumor containing yelloworange fluid with cholesterol crystals (Fig. 2). The tumor capsule was removed, and no residual tumor was found upon inspection of the ventricle and choroid plexus. The patient was discharged on the 3rd postoperative day and made an uneventful recovery. Histological examination was consistent with an adamantinomatous craniopharyngioma. Clinically, the patient's headaches resolved. Postoperative MRI and follow-up MRI scans at 3.5 years

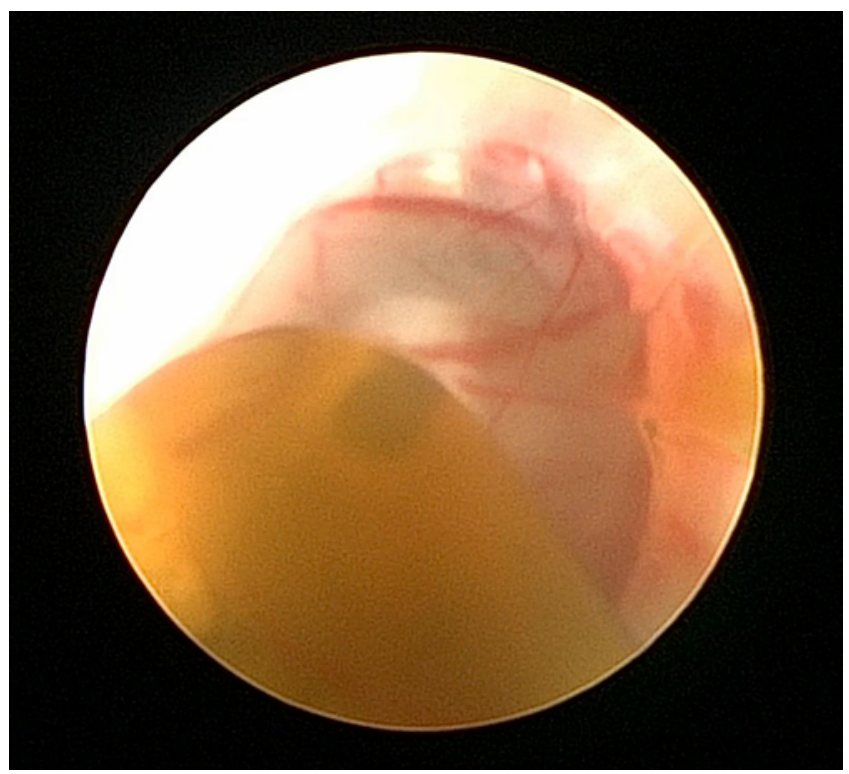

FIG. 2. Intraoperative endoscopic photograph within the left lateral ventricle demonstrating the yellow tumor cyst in the lower portion of the image containing thick, proteinaceous cholesterol crystals. Figure is available in color online only.

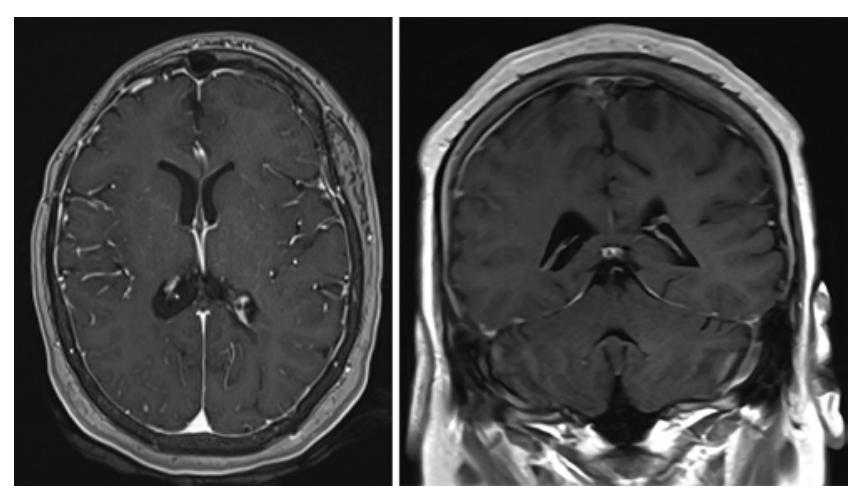

FIG. 3. Postoperative enhanced axial (left) and coronal (right) T1weighted MR images demonstrating stable postoperative changes at the 3.5-year follow-up visit.

showed continued stable appearance of the suprasellar region and ventricle (Fig. 3).

\section{Discussion}

Ectopic recurrence of benign tumors is rare but is reported for several different histologies, including central neurocytoma, choroid plexus papilloma, meningioma, and pituitary adenoma..$^{12}$ The first case of an ectopic recurrence was published in 1978 and since then fewer than 100 cases have been reported in the literature (Table 1). ${ }^{8}$ The best estimate of incidence is from a single-institution report of 4 cases (4.7\%) of ectopic recurrence in 86 consecutive cases of pediatric craniopharyngiomas at a mean follow-up time of 9.5 years. ${ }^{5}$

Our patient presented with an enlarging lesion in the body of the left lateral ventricle 12 years after initial diagnosis. This case represents the first reported patient with a craniopharyngioma that metastasized to the lateral ventricles. Association with the choroid plexus and distant location from the initial surgical site complicated the diagnosis, which included a differential of choroid plexus cyst, choroid papilloma, or ectopic craniopharyngioma recurrence. Endoscopic resection resulted in control of this distant site of disease and no further evidence of new ectopic foci.

Review of the literature for ectopic craniopharyngiomas reveals several trends. Most of the reported cases are in male patients $\mathrm{s}^{13}$ and all underwent a previous craniotomy. Ectopic recurrence following a transsphenoidal approach has yet to be reported despite the fact that this operative approach is used in 39\% of cases. ${ }^{1}$ The majority of ectopic cases demonstrate adamantinomatous histology. Studies quantifying methylation-inhibited binding protein-1 staining for proliferative index have not allowed firm conclusions to be drawn. ${ }^{11}$ Location of ectopic recurrence varies widely, yet the majority of reported cases are masses along the surgical route, most often subdural along the convexities, sylvian fissure, or through the tentorial incisura into the cerebellopontine angle..$^{3,5,7,13,14}$ No clear association with prior radiation therapy is apparent.

The mechanism for tumor seeding is proposed to result from either gross contamination during the time of surgery 


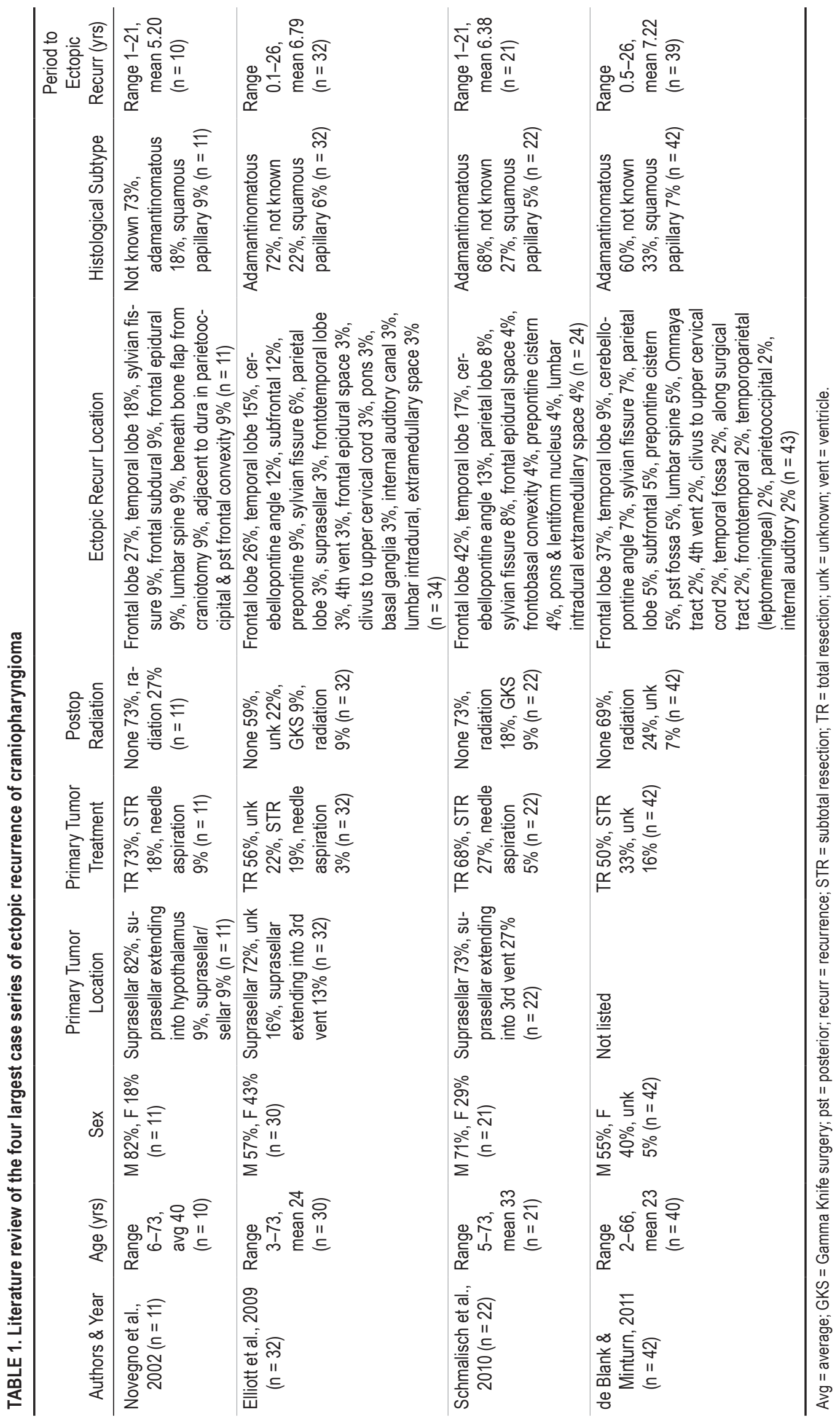


or spillage of tumor contents into the CSF spaces, with circulation and eventual tumor growth after attachment to a distant structure..$^{10}$ Given the apparent association between craniotomies and ectopic seeding, emphasis is placed on meticulous protection of the operative corridor during the operation, with reports of covering the operative field with cotton, early cyst aspiration, and rigorous irrigation prior to closing. ${ }^{13}$ The value of alternative approaches, including endoscopic transcranial and transsphenoidal, if appropriate, may ultimately limit future ectopic recurrences.

On the molecular level, ectopic craniopharyngiomas lose $\mathrm{N}$-cadherin expression compared to index tumors. ${ }^{11}$ The loss of this cell adhesion protein may account for an increased propensity to circulate to distant sites. Additionally, ectopic craniopharyngiomas demonstrated an increased expression of vascular endothelial growth factor and receptor expression in tumor specimens, suggesting a possible role for angiogenesis in distant tumor spread. ${ }^{6}$

The possibility of multiple recurrences, including ectopic recurrences, necessitates long-term follow-up for craniopharyngioma patients, as well as developing a high index of suspicion for atypical, new lesions. Furthermore, given the rarity of metastatic craniopharyngiomas, the need for continued reporting of metastatic spread is imperative to further delineate risk factors, molecular mechanisms, and improved surgical approaches.

\section{References}

1. Baskin DS, Wilson CB: Surgical management of craniopharyngiomas. A review of 74 cases. J Neurosurg 65:22-27, 1986

2. Carmel PW, Antunes JL, Chang CH: Craniopharyngiomas in children. Neurosurgery 11:382-389, 1982

3. de Blank PM, Minturn JE: A rare case of ectopic recurrence of a craniopharyngioma diagnosed 17 years after initial presentation. J Pediatr Hematol Oncol 33:392-397, 2011

4. Duff J, Meyer FB, Ilstrup DM, Laws ER Jr, Schleck CD, Scheithauer BW: Long-term outcomes for surgically resected craniopharyngiomas. Neurosurgery 46:291-305, 2000

5. Elliott RE, Moshel YA, Wisoff JH: Surgical treatment of ectopic recurrence of craniopharyngioma. Report of 4 cases. J Neurosurg Pediatr 4:105-112, 2009

6. Elmaci L, Kurtkaya-Yapicier O, Ekinci G, Sav A, Pamir $\mathrm{MN}$, Vidal S, et al: Metastatic papillary craniopharyngioma: case study and study of tumor angiogenesis. Neuro Oncol 4:123-128, 2002

7. Gökalp HZ, Egemen N, Ildan F, Bacaci K: Craniopharyngioma of the posterior fossa. Neurosurgery 29:446-448, 1991

8. Gonçalves CB, Lima GAB, Nogueira J, do Souto AAD, Chimelli L, Taboada GF: Subgaleal recurrence of craniopharyngioma of rapid growing pattern. Pituitary 17:214-219, 2014

9. Gupta K, Kuhn MJ, Shevlin DW, Wacaser LE: Metastatic craniopharyngioma. AJNR Am J Neuroradiol 20:10591060, 1999

10. Lee DK, Jung HW, Kim DG, Paek SH, Gwak HS, Choe G: Postoperative spinal seeding of craniopharyngioma. Case report. J Neurosurg 94:617-620, 2001

11. Nomura H, Kurimoto M, Nagai S, Hayashi N, Hirashima Y, Tsukamoto E, et al: Multiple intracranial seeding of craniopharyngioma after repeated surgery-case report. Neurol Med Chir (Tokyo) 42:268-271, 2002

12. Novegno F, Di Rocco F, Colosimo C Jr, Lauriola L, Caldarelli M: Ectopic recurrences of craniopharyngioma. Childs Nerv Syst 18:468-473, 2002

13. Schmalisch K, Beschorner R, Psaras T, Honegger J: Postoperative intracranial seeding of craniopharyngiomas - report of three cases and review of the literature. Acta Neurochir (Wien) 152:313-319, 2010

14. Tomita S, Mendoza ND, Symon L: Recurrent craniopharyngioma in the posterior fossa. Br J Neurosurg 6:587-590, 1992

\section{Disclosures}

The authors report no conflict of interest concerning the materials or methods used in this study or the findings specified in this paper.

\section{Author Contributions}

Conception and design: Couture, Carter. Acquisition of data: all authors. Analysis and interpretation of data: all authors. Drafting the article: all authors. Critically revising the article: Couture, Renfrow. Reviewed submitted version of manuscript: Couture. Administrative/technical/material support: Couture. Study supervision: Couture.

\section{Correspondence}

Daniel E. Couture: Wake Forest Baptist Medical Center, WinstonSalem, NC.dcouture@wakehealth.edu. 